\title{
Prenatal prediction of Werdnig-Hoffmann disease using linked polymorphic DNA probes
}

Judith Melki, Sonia Abdelhak, Philippe Burlet, Valérie Raclin, Josseline Kaplan, Roland Spiegel, Simone Gilgenkrantz, Nicole Philip, Marie-Liesse Chauvet, Yves Dumez, Marie-Louise Briard, Jean Frézal, Arnold Munnich

\begin{abstract}
Werdnig-Hoffmann disease is a common autosomal recessive neuromuscular disorder that results in paralysis and death. No treatment to prevent this disease or to alter its unremitting course has been found. Recently, linkage analysis with cloned DNA probes has shown that the mutation causing Werdnig-Hoffmann disease is located on chromosome 5q12q14. We performed genetic analysis for the prenatal diagnosis of WerdnigHoffmann disease in seven at risk families. Two fetuses were diagnosed as being affected and the remainder as unaffected, and this was confirmed after birth. This study shows that prenatal diagnosis of Werdnig-Hoffmann disease has become feasible.
\end{abstract}

The childhood spinal muscular atrophies (SMA) are characterised by degeneration of anterior horn cells of the spinal cord, leading to progressive symmetrical paralysis of the limbs and trunk associated with muscular atrophy. They are the second most common autosomal recessive disease after cystic fibrosis. ${ }^{1}$ Clinical heterogeneity of the different types of the disease in childhood has long been recognised. The childhood form is classically subdivided into three groups, acute Werdnig-Hoffmann (type I), intermediate Werdnig-Hoffmann (type II), and Kugelberg-Welander disease (type III), on the basis of a combination of age of onset, developmental milestones, and age of survival. ${ }^{2}$ The underlying biochemical defect of this devastating paralysing disorder remains unknown and there is no treatment to prevent this disease or to alter its unremitting course. Many families wish to have prenatal diagnosis for subsequent pregnancies. Until recently, no test was available for diagnosis of SMA in families with a 1 in 4 risk of recurrence.

Recently, using genetic linkage analysis, the gene responsible for the three forms of SMA has been mapped to chromosome $5 q$ and five markers, including two flanking DNA probes (M4 and p105-153Ra), are closely linked to the SMA locus. ${ }^{3-7}$ These genetic markers (in the form of DNA polymorphisms shown by restriction endonuclease analysis) are potentially useful for prenatal diagnosis in families with at least one affected child.

Here, we report our preliminary experience with prenatal diagnosis of SMA in seven families using the linked probes on chorionic villi and amniotic fluid during the first and second trimesters of pregnancy.

\section{Families}

Only two of the seven families had living children with Werdnig-Hoffmann disease. Blood samples were available for the other affected children who had died. Medical records were used to confirm the diagnosis of SMA using the following diagnostic criteria: (1) proximal, symmetrical weakness of the limbs and trunk; (2) muscle atrophy without facial or extraocular involvement; (3) no spasticity, hyperreflexia, sensory loss, or mental retardation; (4) electromyographic studies showing denervation and diminished motor action potential with normal or slow nerve conduction velocities ${ }^{8}$; and (5) muscle biopsy showing denervation with no evidence of storage material or other structural abnormalities. ${ }^{9}$

The women were pregnant when requesting prenatal diagnosis. Families were fully counselled before prenatal diagnosis, that is, they were told that it was essential to analyse both parents and their children with the linked probes. It was also explained that the accuracy of prenatal diagnosis would depend on the genetic distance between the markers giving informative meioses and the disease locus (risk calculation)

\section{Methods}

Five families were referred for chorionic villus sampling between 9 and 12 weeks of gestation. The villi were examined microscopically to remove maternal decidual contamination. In two families, fetal material was obtained by midtrimester amniotic fluid sampling.

Nuclear DNA was isolated from leucocytes in $20 \mathrm{ml}$ of EDTA blood, lymphoblastoid cell lines, cultured amniotic fluid cells, or chorionic villi by standard proteinase $K$ treatment and phenol-chloroform extraction techniques and digested with the appropriate restriction enzymes. The characteristics of the DNA probes are described elsewhere ${ }^{7}$ (see appendix). Risk calculations were done with the computer program package LINKAGE. ${ }^{10}$

\section{Results}

Prenatal diagnosis was achieved with data from DNA markers for all families. Two fetuses were diagnosed as being affected, the remainder as unaffected. 
FAMILY A

First cousin parents, with one type II SMA girl and one healthy girl, requested second trimester prenatal diagnosis. The probes p105-153Ra and p105-599Ha allowed us to distinguish which of each parent's chromosomes 5 carried the mutant allele (informative meiosis). The family opted for amniotic fluid sampling (figure A). The fetus was diagnosed as being healthy with a high probability $(99.9 \%)$ and neurological examination at 12 months of age confirmed this.

A

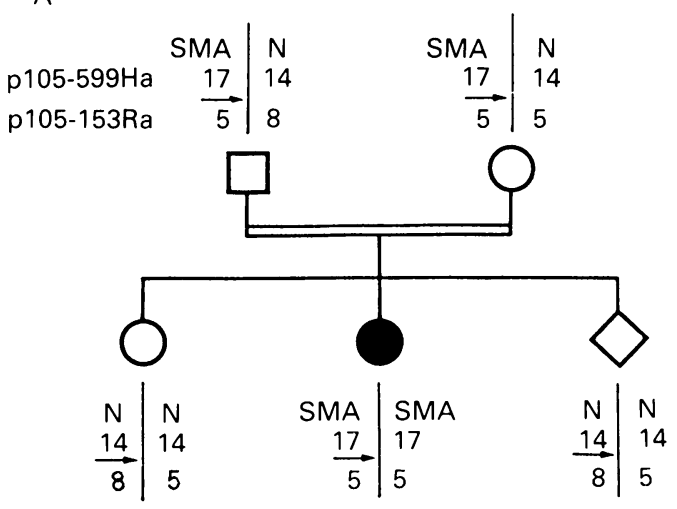

B

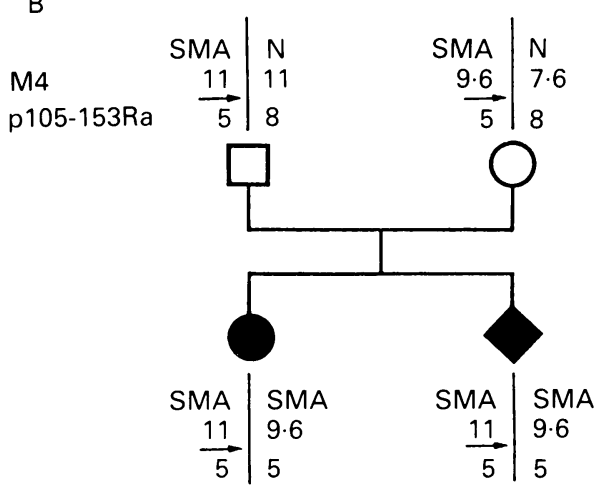

C

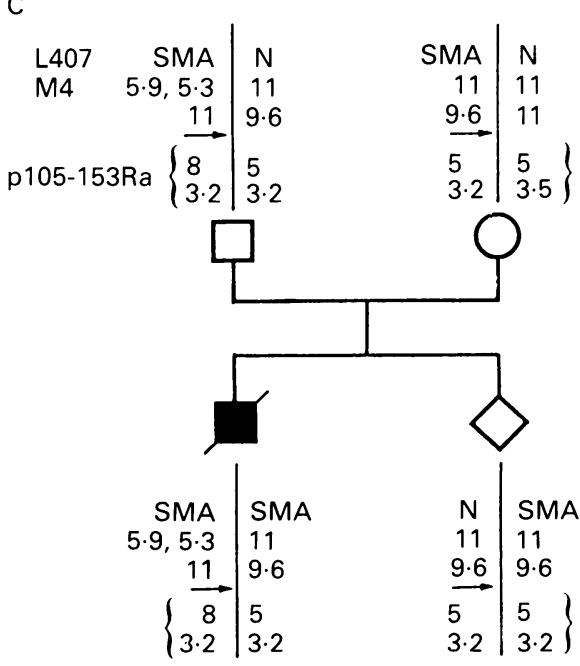

DNA genotyping for families $A, B$, and $C$. Haplotypes are shown with alleles at the SMA locus. Fragment sizes are given in kilobases $(k b)$. The arrow indicates the location of the SMA gene.
FAMILY B

A woman with one type I SMA girl presented at 10 weeks of gestation requesting first trimester prenatal diagnosis. The family was informative for diagnosis with the M4 and p105153Ra polymorphisms and chose first trimester chorionic villus sampling (figure B). The fetus had inherited chromosomes identical to the affected child. The risk calculation averaged $93 \%$ that the fetus would be affected. After counselling, the family chose early suction termination of pregnancy. The product of conception was not suitable for histological examination but has been stored for future analysis.

FAMILY C

A woman whose first son died of type I SMA presented at 9 weeks of gestation requesting first trimester prenatal diagnosis. DNA genotyping showed the family to be informative for diagnosis with the L407, M4, and p105-153Ra probes (figure $\mathrm{C}$ ). The fetus had inherited the same maternal haplotype as the proband and a paternal chromosome likely to carry the normal gene. The fetus was diagnosed as being a carrier for SMA with a normal phenotype. Risk calculation gave a $99.3 \%$ chance that the fetus would be normal. Neurological examination and electromyographic study performed at 6 months of age were normal.

FAMILIES D, E, F, AND G

The results of prenatal diagnosis in four additional families (father, mother, and one dead type I child) are shown in the table. The fetus in family $F$ had a high probability of being affected and was aborted. The fetus in family $\mathrm{D}$ was diagnosed as being a carrier with a normal phenotype. The fetus in family $G$ had a high probability of being healthy; however, his probability of being a carrier was $50 \%$. In family $\mathrm{G}$, the risk calculation took into account the obligate recombination event between p105-599Ha and p105-153Ra on the maternal allele. Neurological examination was normal at 6 months of age (family G), 7 months of age (family D), and 8 months of age (family E).

\section{Discussion}

Until recently, no test was available to allow prenatal diagnosis of SMA in families with a 1 in 4 risk of recurrence. This study shows that prenatal diagnosis of Werdnig-Hoffmann disease has become feasible with different DNA probes linked to the SMA locus. Our experience with the diagnostic application of all available DNA markers clearly illustrates the advantages and problems of this approach.

In families $\mathrm{A}, \mathrm{B}, \mathrm{C}, \mathrm{D}$, and $\mathrm{E}$, the predictions of the fetal genotype were straightforward and were confirmed after birth in the unaffected children. However, there are not yet reliable biological or morphological markers to confirm the affected status of the product of conception. In family $G$, prenatal diagnosis for this partly informative family was 
DNA genotyping in four SMA families. DNA genotypes are shown with fragment sizes in kilobases. Risk calculations are given with the maximum likelihood estimate (brackets) and upper limit of confidence interval (square brackets).

\begin{tabular}{|c|c|c|c|c|c|c|c|c|}
\hline Family & Probe & Father & Mother & $\begin{array}{l}\text { Affected } \\
\text { sib }\end{array}$ & $\begin{array}{c}\text { Unaffected } \\
\text { sib }\end{array}$ & Fetus & Diagnosis & $\begin{array}{l}\text { Probability of } \\
\text { being affected }\end{array}$ \\
\hline D & $\begin{array}{l}\text { M4 } \\
\text { p105-153Ra }\end{array}$ & $\begin{array}{l}9 \cdot 6 / 9 \cdot 6 \\
8 / 5\end{array}$ & $\begin{array}{l}9 \cdot 6 / 7 \cdot 6 \\
8 / 5\end{array}$ & $\begin{array}{l}9 \cdot 6 / 7 \cdot 6 \\
5 / 8\end{array}$ & - & $\begin{array}{l}9 \cdot 6 / 9 \cdot 6 \\
5 / 5\end{array}$ & Carrier & $\begin{array}{l}(0.009) \\
{[0.04]}\end{array}$ \\
\hline $\mathbf{E}$ & $\begin{array}{l}\text { p1 } \\
\text { p105-59 } \\
\text { p105-153Ra }\end{array}$ & $\begin{array}{l}8 / 3 \\
9 / 9 \\
11 / 9 \cdot 6 \\
5 / 5\end{array}$ & $\begin{array}{l}8 / 3 \\
17 / 9 \\
9 \cdot 6 / 9 \cdot 6 \\
8 / 5\end{array}$ & $\begin{array}{l}9 / 8 \\
9 / 9 \\
9 \cdot 6 / 9 \cdot 6 \\
5 / 5\end{array}$ & $\begin{array}{l}- \\
- \\
-\end{array}$ & $\begin{array}{l}7 / 3 \\
9 / 17 \\
11 / 9 \cdot 6 \\
5 / 5\end{array}$ & Carrier & $\begin{array}{l}(0.04) \\
{[0.14]}\end{array}$ \\
\hline $\mathrm{F}$ & & $\begin{array}{l}10 / 10 \\
8 / 5\end{array}$ & $\begin{array}{l}10 / 17 \\
5 / 5\end{array}$ & $\begin{array}{l}10 / 17 \\
5 / 5\end{array}$ & & $\begin{array}{l}10 / 17 \\
5 / 5\end{array}$ & SMA & $\begin{array}{l}(0.85) \\
{[0.70]}\end{array}$ \\
\hline G & $\begin{array}{l}\text { M4 } \\
\text { p105-153Ra }\end{array}$ & $\begin{array}{l}9 \cdot 6 / 11 \\
5 / 8\end{array}$ & $\begin{array}{l}11 / 11 \\
8 / 8\end{array}$ & $\begin{array}{l}11 / 11 \\
8 / 8\end{array}$ & $\begin{array}{l}11 / 11 \\
8 / 8\end{array}$ & $\begin{array}{l}9 \cdot 6 / 11 \\
5 / 8\end{array}$ & $\begin{array}{l}\text { Homozygous } \\
\text { normal or } \\
\text { carrier }\end{array}$ & $\begin{array}{l}(0.0025) \\
{[0.018]}\end{array}$ \\
\hline
\end{tabular}

possible because the fetus had inherited the normal allele from his father. If the DNA genotyping of the fetus had been identical to the proband, then the risk of its being affected would be $50 \%$. Family E illustrates the possible occurrence of a crossover event within this DNA segment. A normal phenotype had been inferred from the phase information for the paternal chromosome. If the fetus had inherited a paternal chromosome identical to that of the affected child, the diagnosis would have been inconclusive.

The experience reported here emphasises the problems of this approach. The accuracy of prenatal diagnosis depends on the genetic distance between the markers and the disease locus, on the orientation of the markers and the disease locus (which is estimated from linkage studies), and the structure of the family. The recombination fraction in risk calculation between DNA probes and $S M A$ may be taken either as the maximum likelihood estimate or more conservatively from the upper limits of the confidence interval. The expected number of families that will be informative for diagnosis may be calculated by established methods. ${ }^{11}$ In about $52 \%$ of cases, both mutant chromosomes can be identified in the parents with at least one of the flanking markers. In these fully informative cases, all affected offspring will be identifiable. In a further $47 \%$, only one parental affected chromosome will be able to be identified with one of the flanking markers. Prenatal diagnosis for these partly informative families can help to predict normal phenotypes. The accuracy of diagnosis of affected offspring could be increased by the other linked probes. Previous analysis of families increases the likelihood of having an optimum set of markers.

The hypothesis of genetic heterogeneity, raised by the observation of unlinked families reported by us $^{7}$ and Gilliam et $a l,{ }^{5}$ has been suggested. Nevertheless, after clinical reinvestigation of these families, atypical findings were observed in association with spinal cord involvement. These include cardiac conduction abnormalities (A Ottolini, personal communication) and marked facial weakness, cataract, and mental retardation. ${ }^{12}$ Thus, genetic heterogeneity can probably be excluded and any unusual presentation of spinal muscular atrophy must be carefully reinvestigated. Strict diagnostic criteria must be followed based on clinical, electromyographic, and muscle biopsy studies before genetic counselling. Another problem is the possible occurrence of phenocopies or recent dominant mutations, suggested by the high incidence of sporadic type II SMA cases, responsible for low segregation ratios. ${ }^{1314}$ Thus, in pedigrees without clear evidence of autosomal recessive inheritance, genetic counselling remains difficult.

Finally, many women have no living affected child which emphasises the importance of DNA banks being established from affected subjects, especially those with SMA type I whose life expectancy is quite short. For this reason, a comprehensive programme of family studies and DNA storage has been undertaken in several countries. When blood, muscle, or other tissue samples are not available from dead affected children, blood collected on filter paper blotters and stored at room temperature (Guthrie cards) can be helpful, since genotypic determination has now become available by PCR amplification using microsatellites. ${ }^{15-17}$ Eventually, the isolation of new polymorphic DNA probes closer to the SMA locus and the identification of the SMA gene itself will allow completely accurate diagnosis.

We gratefully acknowledge the families and the physicians for their constant support. This study was supported by Association Française pour le Dépistage et la Prévention des Handicaps de l'Enfant and funded by grants from the Association Française contre les Myopathies. We thank Monique Poussière and Alan Strickland for their help in preparing this manuscript. The probes p105-153Ra, p105-599Ha, and M4 were purchased from American Type Culture Collection. Probes CRI-L407 and CRI-L1155 were purchased from Collaborative Research Incorporated.

\section{APPENDIX}

The characteristics of DNA polymorphism markers have been previously reported. ${ }^{7}$ The most likely order of loci is D5S76-D5S63D5S6-SMA-D5S39-D5S51. The maximum likelihood estimate of the recombination fraction $(\hat{\theta})$ between the marker and the SMA locus was obtained from linkage study in $\mathbf{5 2}$ SMA families each containing at least two 
affected subjects. The $\hat{\theta}$ with the upper limit of confidence interval (parentheses) are: D5S76: 5\% (10\%); D5S63: 3.6\% (10\%); D5S6: $4.5 \%$ (11\%); D5S39: $3.2 \%$ (8\%); DSS51: $3.3 \%$ $(9 \%)$.

1 Pearn J. Classification of spinal muscular atrophies. Lance 1980;i:919-22.

2 Emery AEH. The nosology of the spinal muscular atrophies. $\mathcal{f}$ Med Genet 1971;8:481-95.

3 Brzustowicz LM, Lehner T, Castilla LH, et al. Genetic mapping of chronic childhood-onset spinal muscular atrophy to chromosome 5q11.2-13.3. Nature 1990; 344:540-1.

4 Melki J, Abdelhak S, Sheth P, et al. Gene for chronic proximal spinal muscular atrophies maps to chromosome 5q. Nature 1990;344:767-8.

5 Gilliam TC, Brzustowicz LM, Castilla LH, et al. Genetic homogeneity between acute and chronic forms of spinal homogeneity between acute and chronic form
muscular atrophy. Nature 1990;345:823-5.

muscular atrophy. Nature $1990 ; 345: 823-5$.
6 Melki J, Sheth P, Abdelhak S, et al. Mapping of acute (type I) spinal muscular atrophy to chromosome 5q12-q14. I) spinal muscular atroph

7 Sheth P, Abdelhak S, Bachelot MF, et al. Linkage analysis in spinal muscular atrophy by six closely flanking markers on chromosome 5. Am f Hum Genet 1991;48:764-8.
8 Moosa A, Dubowitz V. Motor nerve conduction velocity in spinal muscular atrophy of childhood. Arch Dis Child $6 ; 51: 974-7$.

9 Engel WK. Selective and non selective susceptibility of muscle fibre types. Arch Neurol 1970;22:97-117.

10 Lathrop GM, Lalouel JM, Julier C, Ott J. Strategies for multilocus linkage analysis in humans. Proc Natl Acad Sci USA 1984;81:3443-6.

11 Chakravarti A, Buetow KH. A strategy for using multiple linked markers for genetic counseling. Am 7 Hum Genet 1985;37:984-97.

12 Dubowitz V. Chaos in classification of the spinal muscular atrophies of childhood. Neuromuscular Disorders 1991; 1:47-53.

13 Hausmanowa-Petruzewicz I, Zaremba J, Borkowska J. Chronic proximal spinal muscular atrophy of childhood and adolescence: problems of classification and genetic and adolescence: problems of classification
counselling. F Med Genet 1985;22:350-3.

14 Zerres K. Genetic spinaler muskelatrophien. Habilitationsschrift Universität Bonn, 1988 .

15 Lyonnet S, Caillaud C, Rey F, et al. Guthrie cards for detection of point mutations in phenylketonuria. Lancet

16 Mankoo BS, Sherrington R, De La Concha A, et al. Two microsatellite polymorphisms at the D5S39 locus. Nucleic Acids Res 1991;19:1963.

17 Morrison KE, Daniels RJ, Suthers GK, et al. High resolution genetic map around the SMA locus on chromosome 5. Am $\mathcal{F}$ Hum Genet (in press). 